\title{
Microbiota encompassing putative spoilage bacteria in retail packaged broiler meat and commercial broiler abattoir
}

\author{
Lauritsen, Camilla Vester; Sejer Kjeldgaard, Jette; Ingmer, Hanne; Bisgaard, Magne; Christensen, Henrik
}

Published in:

International Journal of Food Microbiology

Link to article, DOI:

10.1016/j.ijfoodmicro.2019.04.003

Publication date:

2019

Document Version

Peer reviewed version

Link back to DTU Orbit

Citation (APA):

Lauritsen, C. V., Sejer Kjeldgaard, J., Ingmer, H., Bisgaard, M., \& Christensen, H. (2019). Microbiota encompassing putative spoilage bacteria in retail packaged broiler meat and commercial broiler abattoir. International Journal of Food Microbiology, 300, 14-21. https://doi.org/10.1016/j.ijfoodmicro.2019.04.003

\section{General rights}

Copyright and moral rights for the publications made accessible in the public portal are retained by the authors and/or other copyright owners and it is a condition of accessing publications that users recognise and abide by the legal requirements associated with these rights.

- Users may download and print one copy of any publication from the public portal for the purpose of private study or research.

- You may not further distribute the material or use it for any profit-making activity or commercial gain

- You may freely distribute the URL identifying the publication in the public portal 


\section{Accepted Manuscript}

Microbiota encompassing putative spoilage bacteria in retail packaged broiler meat and commercial broiler abattoir

Camilla Vester Lauritsen, Jette Kjeldgaard, Hanne Ingmer, Magne Bisgaard, Henrik Christensen

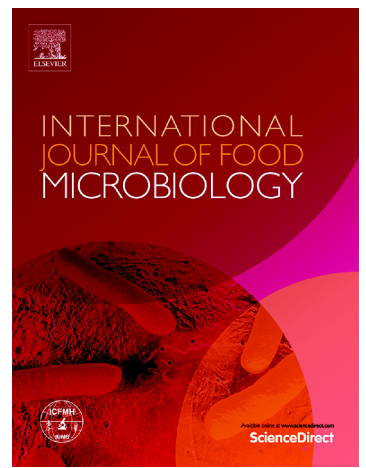

PII:

S0168-1605(19)30096-0

DOI: https://doi.org/10.1016/j.jijfoodmicro.2019.04.003

Reference: FOOD 8206

To appear in: International Journal of Food Microbiology

Received date: 7 December 2018

Revised date:

19 March 2019

Accepted date:

9 April 2019

Please cite this article as: C.V. Lauritsen, J. Kjeldgaard, H. Ingmer, et al., Microbiota encompassing putative spoilage bacteria in retail packaged broiler meat and commercial broiler abattoir, International Journal of Food Microbiology, https://doi.org/10.1016/ j.ijfoodmicro.2019.04.003

This is a PDF file of an unedited manuscript that has been accepted for publication. As a service to our customers we are providing this early version of the manuscript. The manuscript will undergo copyediting, typesetting, and review of the resulting proof before it is published in its final form. Please note that during the production process errors may be discovered which could affect the content, and all legal disclaimers that apply to the journal pertain. 


\section{Microbiota encompassing putative spoilage bacteria in retail packaged broiler meat and commercial broiler abattoir}

Camilla Vester Lauritsen ${ }^{\text {a }}$, Jette Kjeldgaard ${ }^{\text {a,b }}$, Hanne Ingmer ${ }^{\text {a }}$, Magne Bisgaard ${ }^{\mathrm{c}}$, Henrik

Christensen $^{\mathrm{d}, *}$

${ }^{\text {a }}$ Section for Food Safety and Zoonoses, Department of Veterinary and Animal Sciences, University of Copenhagen, Stigbøjlen 4, 1870 Frederiksberg C, Denmark

${ }^{\mathrm{b}}$ Research Group for Genomic Epidemiology, National Food Institute, Technical University of Denmark, Kemitorvet, 2800, Kgs. Lyngby, Denmark

${ }^{\mathrm{c}}$ Horsevænget 40, 4130 Viby Sjælland, Denmark

${ }^{\mathrm{d}}$ Section for Veterinary Clinical Microbiology, Department of Veterinary and Animal Sciences, University of Copenhagen, Stigbøjlen 4, 1870 Frederiksberg C, Denmark

* Corresponding author.

E-mail addresses: cvlau@sund.ku.dk (Camilla V. Lauritsen), jetk@ food.dtu.dk (Jette Kjeldgaard), hi@sund.ku.dk (Hanne Ingmer), m.bisgaard@post.tele.dk (Magne Bisgaard), hech@ sund.ku.dk (Henrik Christensen).

Color should be used for all figures in print

Declarations of interest: none 


\section{Abstract}

It is well established, that certain bacteria within the Brochothrix, Carnobacterium, Lactobacillus, Lactococcus, and Leuconostoc genera have an important role in the spoilage of chill stored poultry meat packaged in modified atmosphere. However, little is known about the role of microorganisms that are difficult to culture and the microbiota during poultry spoilage. We combined traditional cultivation and culture-independent $16 \mathrm{~S}$ rRNA amplicon sequencing to investigate the microbiota encompassing putative bacteria of whole broiler meat, packaged in modified atmosphere, during and exceeding shelf-life. Samples were taken from 6 flocks during independent slaughter days. Additional samples were analysed from the production line. There was a significant difference in the microbial community structure of $80 \% \mathrm{O}_{2} / 20 \% \mathrm{CO}_{2}$ retail packaged broiler meat during different times of shelf-life, mainly due to an increase of species within the Brochothrix, Carnobacterium, Vagococcus, and Janthinobacterium genera. These genera were already detected four to eight days after slaughter. However, no significant difference between flocks with respect to the microbiota encompassing putative spoilage bacteria was observed when examined in retail packaged broilers, slaughtered at the same abattoir on different days. Our study also showed that lactic acid bacteria within the Vagococcus genus can constitute a dominating part of the later shelf-life microbiota in fresh whole broiler meat packaged in $80 \% \mathrm{O}_{2} / 20 \% \mathrm{CO}_{2}$ modified atmosphere. A single operational taxonomic unit (OTU) assigned as Janthinobacterium lividum, an occasional spoiler of meat products, was identified as a major part of the microbiota in late shelf life broiler meat and swab samples in the cooling facility at the slaughter house production line. The combination of traditional cultivation and culture-independent methods provided a great insight into the microbiota of broiler meat during shelf-life and identified a potential point of contamination in the production line for cold tolerant Janthinobacterium. 
Keywords: Poultry spoilage, 16S rRNA amplicon sequencing, retail broiler, Janthinobacterium, production line, shelf-life

\section{Introduction}

Microbial spoilage is a key factor for the limitations in the shelf-life of fresh poultry meat. The shelf-life of retail poultry meat is short, normally up to around 10 days (Jimenez et al., 1997). However, some producers have reported an acceptable shelf-life of more than two weeks for their retail packaged broiler meat. Important parameters when ensuring long shelf-life are production hygiene, storage temperature and packaging method (Doulgeraki et al., 2012). High $\mathrm{CO}_{2}$ modified atmosphere packaging (MAP) probably inhibits growth of strictly aerobic microorganisms and prolongs the shelf-life of fresh meats. However, some lactic acid bacteria and Brochothrix thermosphacta can grow in high $\mathrm{CO}_{2} \mathrm{MAP}$, and they can spoil meat products by formation of sour smells and sometimes slime (Doulgeraki et al., 2012; Nieminen et al., 2015; Rahkila et al., 2012). Studies on meat spoilage have focused on cultivable microorganisms and have identified Gram negatives such as Pseudomonas spp. and Acinetobacter spp., together with Flavobacterium spp. and some Enterobacteriaceae in aerobically packaged meat (Daud et al., 1979; Doulgeraki et al., 2012; Jimenez et al., 1997; Liang et al., 2012; Sade et al., 2013).). In MAP, the predominant microorganisms involved in spoilage of poultry meat have been identified as the Gram positive Brochothrix thermosphacta and lactic acid bacteria within the Carnobacterium, Lactococcus, Lactobacillus and Leuconostoc genera (Barakat et al., 2000; Jimenez et al., 1997; Koort et al., 2005; Sade et al., 2013). Many microorganisms are not easily cultivable and it remains unknown what their role is in poultry meat spoilage, even though they might influence spoilage directly or indirectly. Recent studies of seafood and meat by culture-independent methods have provided a 
greater insight into their microbiota (Chaillou et al., 2015; Nieminen et al., 2012; Nieminen et al., 2015; Powell and Tamplin, 2012; Rouger et al, 2018). In the present study we aim to determine the microbiota of poultry meat during and exceeding shelf-life, by culture-independent 16S rRNA amplicon sequencing.

We considered two hypotheses to explain the composition of microbiota on fresh whole broiler meat. Hypothesis one being that the microbiota is diverse between retail meat from different broiler flocks, slaughtered and packaged at the same abattoir on different days of slaughter. The idea being that the live broilers carry different initial microbiota, from the farms into the slaughter line, in which case we would investigate, which potential poultry meat spoilers different flocks carry into the production line and what influence it has on the spoilage microbiota during and exceeding shelf-life. The alternative hypothesis is that the microbiota composition is not different between retail meat from different broiler flocks, when slaughtered and packaged at the same abattoir, and under these circumstances we should be able to identify a core microbiota encompassing putative spoilage bacteria and identify critical points in the slaughterhouse production line for important poultry meat spoilers.

To test both hypotheses we collected samples of whole retailed packaged broiler meat from different flocks in a single poultry abattoir on different days in which we compared the composition of the microbiota during and exceeding shelf-life by 16S rRNA amplicon sequencing. As the microbiota encompassing putative spoilage bacteria was quite similar between flocks, slaughtered and packaged under similar circumstances over a four month period, we defined a core microbiota encompassing putative spoilage bacteria and tried to identify potential contamination points in the slaughterhouse production line. 


\section{Material and methods}

\subsubsection{Retail sampling}

Samples of whole broiler meat from five broiler flocks, six per flock, retail packaged in $80 \% \mathrm{O}_{2} / 20 \% \mathrm{CO}_{2}$ were collected at five different days of slaughter at a commercial Danish poultry slaughterhouse between February and May 2015. All flocks originated from different primary production farms. The packages were kept cool $\left(5-8^{\circ} \mathrm{C}\right)$ and transported to the laboratory as quickly as possible (6-9 hours). At arrival, samples were stored at $6{ }^{\circ} \mathrm{C}$ until further sampling. The storage temperature was chosen to represent storage conditions at retail distribution. Broilers were sampled either $0,4,8,10,12$ and 16 days after slaughter, respectively. Six whole retail packaged broilers were sampled from a single flock of a Norwegian slaughterhouse, packaged in $50 \% \mathrm{~N}_{2} / 50 \% \mathrm{CO}_{2}$. Norwegian broiler carcasses were transported to the laboratory at $5-8{ }^{\circ} \mathrm{C}$ as quickly as possible (16 hours) to be analysed in Denmark and broilers were sampled either 1, 4, 8 , 10,12 and 16 days after slaughter, respectively.

\subsubsection{Production line sampling}

Four broiler carcasses were collected during the slaughter of the second flock slaughtered on the third sampling day. Broiler carcasses were taken immediately after scalding at $55{ }^{\circ} \mathrm{C}$, directly after feather plucking, immediately after evisceration, and in the middle of the cooling chain. Carcasses were kept cool $\left(5-8{ }^{\circ} \mathrm{C}\right)$ and returned as quickly as possible to the laboratory $(12-15$ hours) for further processing (see $2.3,2.4$ ).

Swab samples were taken from the production line during the slaughter of the sampled retail broiler flock on the third sampling day at the Danish abattoir, at scalding, feather plucking, 
evisceration of intestinal organs, and in the cooling chain. Two additional swab samples were taken in the cooling condenser at sampling day 1 and $4 \mathrm{in}$. The $55^{\circ} \mathrm{C}$ scalding tub was sampled by dipping sterile tampons (Easy, Dansk Supermarked, Denmark) into the tub for 1 minute and thereafter placed in a $50 \mathrm{~mL}$ sterile plastic tube. The rubber plucking fingers were sampled by thoroughly rubbing with a sterile cloth soaked with $0.1 \%$ peptone solution (A04121A, Food Diagnostics, Denmark) and returned to the sterile resealable packaging. The eviscerator knife was sampled by stopping the machine for 5 minutes and thoroughly swabbing knifes with a cotton swab soaked in maximum recovery diluent (MRD) (MW7969, MWE, England). In the cooling chain, an area of approximately $10 \times 10 \mathrm{~cm}$ on the grid of the central cooling condensor, was thoroughly swabbed using a cotton swab soaked in MRD (MW7969, MWE, England). Samples were kept cool $\left(5-8{ }^{\circ} \mathrm{C}\right)$ and returned as quickly as possible to the laboratory (12-15 hours) for further processing (see $2.3,2.4)$.

\subsection{Sensory evaluation}

Organoleptic changes of whole raw broilers were evaluated by a trained person 10 minutes after opening of the retail packaged broilers. The slime formation, odour, colour, and overall acceptability was evaluated and scored. The slime formation was scored as $1=$ No slime, $2=\mathrm{A}$ little slime, but still acceptable, or $3=$ Clear slime layer, unacceptable. Odour was scored as $1=$ Fresh, 2 $=$ Some off-odour, but still acceptable, 3 = Clear off-odour, unacceptable, or $4=$ Clearly deviating off-odour, unacceptable, and it was noted if the odour could be described as sour, sulphurous, or putrid. Colour, such as browning or whitening of the meat, was scored as $1=$ No discolouration, $2=$ Starting discolouration, acceptable, $3=$ Clear discolouration, unacceptable, or $4=$ Clearly deviating 
colour, unacceptable. The overall acceptability for consumption was then evaluated and scored acceptable/not acceptable.

\subsection{Cultivation based methods}

Carcasses and whole broiler meat samples were rinsed in $500 \mathrm{~mL}$ sterile saline water $(0.9 \%)$ and shaken thoroughly for 1 minute. Swab sample replicates were pooled into one sample for each sampling point and flock. Sterile saline water $(0.9 \%)$ was added to the scalding tampon samples in a 1:1 w/v scale. Cloth samples from the plucking fingers were weighed and sterile saline water added in $1: 9 \mathrm{w} / \mathrm{v}$. Each of the cotton swabs was in $10 \mathrm{~mL}$ maximum recovery dilutant. The rinse water from each retail broiler, carcass and swab samples, were diluted to a countable range in saline $(0.9 \%)$ peptone buffered $(0.1 \%)$ water, and total viable psychrotrophic, and for retail broiler also selective counts, were plated in duplicates for each sample. One $\mathrm{ml}$ of appropriate dilutions in plate count agar pour plates (PCA) (CM0325B, Oxoid, Thermo Fisher Scientific Inc., USA) were incubated at $6.5^{\circ} \mathrm{C}$ for 10 days. The deep seed in the pour plates will include anaerobic conditions. Selective media were seeded with $100 \mu \mathrm{l}$ of the appropriate dilutions. MacConkey agar (MC) (105465, Merck Millipore, Germany) was incubated for 10 days at $6.5^{\circ} \mathrm{C}$. This medium is indicative of Gram negative enteric bacilli. Enrichment for lactic acid bacteria was performed on de Man, Rogosa and Sharpe agar (MRS) (CM0361, Oxoid, Thermo Fisher Scientific Inc., USA) incubated at $20{ }^{\circ} \mathrm{C}$ for 3 days in normal atmosphere. Streptomycin thallous acidione agar (STAA) (CM0881B, Oxoid, Thermo Fisher Scientific Inc., USA) with supplement (SR0151E, Oxoid, Thermo Fisher Scientific Inc., USA) with incubation at $20^{\circ} \mathrm{C}$ for 3 days was used for indicative enrichment of Brochothrix thermosphacta. 
Viable counts of whole retail broilers samples were converted to $\mathrm{CFU} / \mathrm{cm}^{2}$, by using the relationship between carcass weight and surface area (Thomas, 1978).

\subsection{Microbial Community Structure}

\subsubsection{DNA extraction}

DNA was extracted from 45 samples (supplementary Table 1) which included rinse water samples from 35 retail chicken, four carcases and six swab samples. DNA was extracted with the PowerLyzer PowerSoil DNA isolation kit (Mobio, USA) following the manufacturers protocol, except using the pellet from spun down rinse water, beat beading for 10 minutes using a vortex adaptor (Mobio, USA), and final elution in nuclease free water (Thermo Fisher Scientific Inc., USA). Extracted DNA was stored at $-20^{\circ} \mathrm{C}$ throughout storage for a maximum of two months prior to PCR amplification.

\subsubsection{S rRNA amplicon sequencing}

Microbial community structure was investigated by $16 \mathrm{~S}$ rRNA amplicon sequencing of total extracted DNA. Samples were sequenced on an Illumina MiSeq (Caporaso et al., 2012) at DNAsense (Aalborg, Denmark), using primers targeting the V1-3 variable region (27F 5'AGAGTTTGATCCTGGCTCAG-3' and 534R 5'-ATTACCGCGGCTGCTGG-3') on the 16S rRNA gene (Ward et al., 2012). The negative control was without DNA template and showed $<0.5$ $\mathrm{ng} / \mu \mathrm{L}$ measured by Qubit 2.0. 


\subsubsection{Microbiota data analysis}

De-multiplexed sequences were received as paired-end reads $(2 \times 301 \mathrm{bp})$ in Fastq format. Sequence data were analysed in Ubuntu terminal using the UPARSE Utax workflow (Edgar, 2013), merging raw reads to a length of minimum 425bp and maximum 525bp (maxee 3.0), dereplicating reads to filter away sequences only seen once in the whole dataset, mapping reads of minimum $97 \%$ identity (maxaccepts 8, maxrejects 64) into operational taxonomic units (OTU) and in the process also removing chimeras. OTUs were classified in the MiDAS database, a curated version of the SILVA database (McIlroy et al., 2015), using an Utax cut off value of 0.5. Rarefaction, exploratory analysis and visualisation of data, was performed in Rstudio (RStudioTeam, 2015) using the Ampvis package (Albertsen et al., 2015). To investigate relationships between flocks, time after slaughter, and the given microbiota on OTU level, multivariate statistics using the "output = complete" function in Ampvis was used to get the p-value of correlation between the given variables and microbial community structure. To resolve the classified OTUs obtained by $16 \mathrm{~S}$ rRNA amplicon sequencing down to species level, sequences of dominating OTUs during shelf-life, were analysed in the EzTaxon-e 16S rRNA gene database (Kim et al., 2012).

\section{Results}

\subsection{Acceptable shelf-life}

Organoleptic acceptable shelf-life varied between 8-12 days for the Danish broiler flocks (Fig. 1 and Supplementary Fig. 1). The acceptable organoleptic shelf life for Norwegian broilers was above 12 days. The main reason for rejection was sour smell formation for all six flocks, while additional unacceptable colour change and slime formation spoiled the product after 12-16 days. When the broilers were evaluated as spoiled, the total viable counts had reached around $10^{7}-10^{8}$ 
$\mathrm{CFU} / \mathrm{cm}^{2}$, a 5-6 $\log _{10}$ increase from day 0 (Fig. 2). Colony counts on MRS, STAA, and MC agars were around $10^{6}-10^{7} \mathrm{CFU} / \mathrm{cm}^{2}$ when products were evaluated as spoiled, indicating a high number of lactic acid bacteria, presumptive Brochothrix, and presumptive Gram negative enteric bacteria on the spoiled broiler meat (Supplementary Fig. 2).

The Norwegian broilers generally had lower microbial counts than the Danish broilers, only reaching a total viable count $>10^{7} \mathrm{CFU} / \mathrm{cm}^{2} 16$ days after slaughter, and also had a longer organoleptic acceptable shelf-life (Fig. 2, Supplementary Fig. 2).

\subsection{Microbiota identified by $16 \mathrm{~S}$ rRNA amplicon sequencing}

16S rRNA amplicon sequencing of total DNA extracted yielded a total of 2,378,672 individual raw sequences, with a median of 50,769 raw reads per sample (variation 2,413-255,754) (Supplementary Table 1). The 664,754 read pairs were merged and $89.1 \%$ of these were mapped into 734 different OTUs (mean sequences mapped/sample = 12,876, variation 1,753-35,751) after removal of singletons and chimeras (Supplementary Table 1). The sequences have been deposited with SRA at NCBI (https://www.ncbi.nlm.nih.gov/) under accession number PRJNA523688 and BioSample accession SAMN10986241. Sufficient sampling depth was verified by rarefaction curves (supplementary Fig. 3) which flattened out around 1,890 sequences, with around 25 to 250 OTUs represented per sample. The sequence analysis indicated a high number of different OTUs in the fresh retail broiler meat (day 0-4) while the older meat has lower diversity of OTUs (Fig. 3). 


\subsubsection{Microbiota of retail broilers during shelf-life}

The phylogenetic structure of the broiler meat microbiota was investigated by assigning OTUs into bacterial genera. The microbiota on OTU level was significantly different between the days after slaughter $(\mathrm{p} \leq 0.001)$, while there was no significant difference between flocks for the five broiler flocks on the same day of shelf life after slaughter $(p=0.847)$. Principal component analysis of the microbiota data revealed that for retail broiler meat samples, the different days of slaughter group together in three groups centred around day 0, day 4 and day 8-16 samples (Supplementary Fig. 4).

On the Norwegian broiler flock, lactococci was a dominating part of the microbiota encompassing putative spoilage bacteria, mainly represented by OTU_11 on day 10-16, which was 98.4\% identical to Lactococcus piscium CCUG $32732^{\mathrm{T}}$, and to a lesser degree an OTU, which was 99.4\% identical to Lactococcus raffinolactis DSM $20443^{\mathrm{T}}$. On Danish broilers only one lactococcus (OTU_11) had a relative abundance of $0.7-1.9 \%$ four to 16 days after slaughter. While their relative abundance might be different during shelf-life, the same OTU sequences for the different putative spoilage bacteria genera Lactococcus, Carnobacterium, Brochothrix, and Janthinobacterium, were identified in both Danish and Norwegian retail broiler samples (data not shown).

On phylum level, the microbiota in all broiler meat samples was clearly dominated by Firmicutes, and to a lesser degree Proteobacteria and Bacteroidetes (Fig. 4). The initial microbiota was very diverse with more than 150 different OTUs represented. A few genera, Lactobacillus and Bacillus of the Firmicutes, and the Bacteriodetes members Chryseobacterium and Flavobacterium were relatively more abundant to all flocks on the very fresh broilers (day 0-4), however, their relative abundance rapidly decrease to less than $0.5 \%$ of the broiler microbiota in older meat samples (Fig. 4). A few genera started to dominate the broiler microbiota already four days after 
slaughter. They were core OTUs on all flocks but had low relative abundance $(\leq 1 \%)$ at day zero. The dominant genera from day eight and exceeding acceptable shelf-life included members of the Firmicutes Brochothrix, Carnobacterium and Vagococcus, and less pronounced the proteobacterial genus Janthinobacterium. This genus increased to a high abundance in the spoiled broiler meat samples (Fig. 5). The genera Pseudomonas and Acinetobacter (assigned as 16S rRNA indistinguable Pseudomonas fragi group and A. harbinensis), within the Proteobacteria phylum, had a low relative abundance on the broiler meat during the whole sampling period (Fig. 5). One OTU was assigned to the Leuconostoc genus and had a low relative abundance which was stable during shelf-life.

The Norwegian flock had a significantly $(\mathrm{p} \leq 0.001)$ different microbiota compared to the Danish flocks, it is however unknown if the difference in packaging atmosphere, abattoir production hygiene, and/or primary production differences is the cause. The main difference being, an initial microbiota dominated by the proteobacteria Polaromonas and Janthinobacterium, and the bacteroidetes Flavobacterium, and a later shelf-life microbiota dominated by Carnobacterium, Lactococcus, and Janthinobacterium on the Norwegian broiler meat (Supplementary Fig. 5).

\subsubsection{Species level}

For the Danish samples, only one OTU (OTU_1) classified as Brochothrix in the MiDAS database, had $100 \%$ identity to Brochothrix thermosphacta type strain DSM $20171^{\mathrm{T}}$ in the EzTaxon-e database. Two OTUs were classified in the Carnobacterium genus (OTU_2 and OTU_14), with the relative abundance of OTU_2 being around 4-5 times higher than OTU_14. OTU_2 had $99.8 \%$ identity to Carnobacterium maltaromaticum DSM $20342^{\mathrm{T}}$, while OTU_14 had a $100 \%$ identity to Carnobacterium divergens DSM $20623^{\mathrm{T}}$. Eight OTUs were classified to the 
Vagococcus genus in the MiDAS database and of these, two OTUs (OTU_7 and OTU_36), were much more prevalent in the mid/late shelf-life compared to early shelf-life, especially OTU_7 (Fig. 3). The remaining six Vagococcus OTUs had very low relative abundances during shelf-life ( $\leq$ 0.8\%). OTU_7 had $98.4 \%$ identity to Vagococcus fluvialis CCUG $32704^{\mathrm{T}}$ and OTU_36 99.8\% identity to Vagococcus salmoninarum CCUG $33394^{\mathrm{T}}$. Only one OTU (OTU_4) was classified to the Gram negative Janthinobacterium genus, and the sequence had $100 \%$ identity to Janthinobacterium lividum DSM $1522^{\mathrm{T}}$.

The lactobacilli found to be very abundant on the fresh broiler meats (day 0-4), consisted mainly of three OTUs, namely OTU_3, OTU_6, and OTU_13, while they were quickly outgrown and had a relative abundance $<0.1 \%$ in later and exceeding shelf-life (Fig. 5). OTU_6 had 100\% identity to Lactobacillus crispatus DSM $20584^{\mathrm{T}}$, OTU_3 had $99.6 \%$ identity to Lactobacillus salivarius ATCC $11741^{\mathrm{T}}$, and OTU_13 had $99.6 \%$ identity to Lactobacillus johnsonii ATCC $33200^{\mathrm{T}}$. The relative abundance of two other Lactobacilli OTUs increased from less than $0.1 \%$ in fresh broiler meat to around $0.2-0.4 \%$ at day 16 . One was $100 \%$ identical to Lactobacillus fuchuensis JCM $11249^{\mathrm{T}}$ and the other $100 \%$ identical to Lactobacillus oligofermentas AMKR18 ${ }^{\mathrm{T}}$ ), respectively.

A potential environmental pathogen was identified, but with a low relative abundance. Within the Enterobacteriaceae family, one OTU classified in the genus Serratia, was found $99.6 \%$ identical to Serratia liquefaciens ATCC $27592^{\mathrm{T}}$, within the indistinguishable $16 \mathrm{~S}$ rRNA liquefaciens group, consisting of S. liquefaciens, Serratia grimesii, and Serratia proteamaculans. Some strains of Serratia liquefaciens can be pathogenic, causing urinary tract, bloodstream infections, meningitis, and pneumonia in human, but outbreaks are normally associated with nosocomial infections due to poor hygiene (Mossad, 2000). The Serratia OTU had a low relative abundance, but was found highest 16 days after slaughter (0.1-0.4\%) (Fig. 5). 


\subsection{Possible contaminations from the production line}

The CFUs from the swab samples of the production line were of qualitative nature and originated from different sampling sites in the production chain and different sampling days. We recovered and identified some of the previously described microbiota encompassing putative spoilage bacteria in the production line. There were significant differences in the microbiota of swab samples between the four different sampling places in the production line $(p \leq 0.001)$ and principal component analysis clearly separated the different sampling places (Fig. 6). The scalding tub was dominated by Bacillus (OTU_12) and Lactobacillus (OTU_3, OTU_6, and OTU_13) OTUs, and to a minor degree also Staphylococcus (OTU_29) and Streptococcus (OTU_59) (Fig. 3). The Bacillus (assigned as B. thermoamylovorans) and Lactobacillus (assigned as L. salivarius, L. crispatus, and L. johnsonii) OTUs identified in the scalding tub were found in all four swab sampling places, but they were only dominating in the scalding tub and only identified on the broiler meat samples on day 0 and 4 after slaughter. The swab sample from the feather plucking fingers was dominated by Bacillus (OTU_ 8 assigned B. cereus) and Streptococcus OTUs (OTU_21, OTU_23, and OTU_25) which was different from the scalding tub and an OTU assigned to the Macrococcus genus (OTU_22) (Fig. 3). In the eviscerator swab sample, three OTUs dominated, namely Lactococcus (OTU_9 assigned L. garvieae), and to some degree two Streptococcus and Bacillus OTUs also identified on the plucking fingers (Fig. 3). The cooling condenser swab samples were dominated by psychrotrophic bacteria. The Janthinobacterium OTU (OTU_4), assigned to J. lividum, was found in high abundance on spoiled broiler meat, in the swabs taken from the cooling condenser and on carcasses taken in the cooling chain (Fig. 3). Other major parts of the cooling condenser microbiota identified by $16 \mathrm{~S}$ rRNA amplicon sequencing, included the genera Chryseobacterium, Polaromonas, and Rhodoferax (Fig. 3 and 6), however, these genera 
were not part of the microbiota on the spoiled broiler meat, and they were quickly outgrown on the fresh retail broiler meat

A single OTU (OTU_12) within the Bacillus genus was dominating (>69\%) in the microbiota of carcasses taken from the scalding tub and the scalding tub itself, but already after plucking the relative abundance of Bacillus decreased to less than $2 \%$. The three Lactobacillus OTUs (assigned as L. crispatus, L. salivarius, and L. johnsoni) readily identified on the very fresh (day 0) retail broiler meat, were found as a dominating part of the microbiota throughout the production line, especially on the broiler carcasses, but also as part of the production line equipment microbiota, however these were quickly outcompeted on the broiler meat during shelf life (Fig. 3).

The dominating OTUs from the later shelf-life retail broilers, Carnobacterium, Brochothrix and Vagococcus were not readily detected by $16 \mathrm{~S}$ rRNA amplicon sequencing in the production line on either carcasses or equipment (Fig. 3). The Brochothrix OTU was detected in all swab and carcass samples, except the scalding tub swab, with a prevalence of $<0.1 \%$. The two Vagococcus OTUs and the Carnobacterium OTU assigned as $C$. divergens, found in high relative abundance on the late shelf life broiler meat, were not detected in any of the swab or carcass samples. The OTU assigned as $C$. maltaromaticum, found readily on the late shelf life broiler meat, was only identified in the production in a swab sample from the feather plucking fingers, with a prevalence of $<0.1 \%$. OTUs within the genera Pseudomonas, Acinetobacter, and Serratia were not detected by 16S rRNA amplicon sequencing in the production line and on slaughter line carcasses.

\section{Discussion}

For the first time, we show that members of the lactic acid bacterial genus Vagococcus form a major part of microbiota in fresh whole broiler meat packaged in modified atmosphere. Most 
likely the species $V$. fluvialis and $V$. salmoninarum were the dominant members of the genus. There has been very limited evidence of the role of members within the Vagococcus genus in meat spoilage, but the genus has been identified in MAP packaged fish (Chaillou et al., 2015; Powell and Tamplin, 2012), spoiled cooked shrimp (Jaffres et al., 2010), and in one case also from brined MAP packaged broiler filets (Nieminen et al., 2012). Some lactic acid bacteria can be difficult to cultivate (Leisner et al., 2007), and it might be the reason for the limited knowledge of the spoilage potential of vagococci, but as we found it as a dominating part of the broiler meat late shelf-life microbiota in high $\mathrm{O}_{2}$ /high $\mathrm{CO}_{2}$ MAP. Further investigations of the role of members of Vagococcus in poultry meat spoilage, direct or indirect, are desirable.

The spoilage potential of $B$. thermosphacta in meat is well known as very potent, and we found it to quickly increase during shelf-life and form a major part of the microbiota in spoiled broiler meat. The spoilage activity of members of the Carnobacterium genus can vary, but the species $C$. maltaromaticum and $C$. divergens identified here in high relative abundance on the spoiled broiler meat, have often being associated to meat spoilage (Leisner et al., 2007). The route of contamination for these two Carnobacterium species have previously been shown to stem from the abattoir production environment and not the incoming broiler flocks (Vihavainen et al., 2007), however, we were not able to easily detect Carnobacterium on the carcasses or equipment in the production line. We were also not able to easily detect Brochothrix and Vagococcus by $16 \mathrm{~S}$ rRNA amplicon sequencing of samples taken in the production line on either carcasses or equipment. The relative abundance of Carnobacterium, Vagococcus, and Brochothrix on the very fresh retail broiler meat was low contrary to recent studies that showed a dominance of membes of Brochothrix, Pseudomonas and Carnobacterium on French chicken cuts stored at various MAP conditions (Rouger et al., 2018). 
Known spoilers within the Gram negative bacteria, such as certain Pseudomonas and Acinetobacter species, are typically associated with conventionally aerobically packaged meat (Liang et al., 2012), so it is no surprise that we found their relative abundance very low in the MAP packaged retail broiler meat during shelf-life. However, we find the Gram negative Betaproteobacteria Janthinobacterium, likely J. lividum, as a dominating part of the broiler microbiota under spoilage conditions in both $80 \% \mathrm{O}_{2} / 20 \% \mathrm{CO}_{2}$ and $50 \% \mathrm{~N}_{2} / 50 \% \mathrm{CO}_{2} \mathrm{MAP}$. $J$. lividum has previously been described as a milk spoiler (Eneroth et al., 2000) and occasionally meat spoiler (Penney et al., 1993), associated with production of the pigment violacein and slime formation. Our results indicated that the cooling condenser in the broiler abattoir production line was potential major route of contamination with J. lividum.

The microbiota encompassing putative spoilage bacteria composition was not significantly different between meat from different broiler flocks, when slaughtered and packaged at the same abattoir, independent of day of slaughter. The microbiota encompassing putative spoilage bacteria composition on broiler meat from a different abattoir (Norway), packaged in a different modified atmosphere is, however different. Broiler meat from Norway packaged in $50 \% \mathrm{~N}_{2} / 50 \% \mathrm{CO}_{2} \mathrm{MAP}_{\text {, }}$ had longer shelf-life, lower CFUs during shelf-life, and a lower relative abundance of Brochothrix and Vagococcus compared to the Danish samples. It has previously been shown that certain Lactobacillus and Lactococcus species, such as L. salivarius, have a potential as protective cultures against spoilage bacteria, as for instance the potent spoiler B. thermosphacta (Rahkila et al., 2012), which together with the lower CFU count could explain the longer shelf life we found in the Norwegian broiler meat. Our findings support that abattoir production line hygiene and composition of packaging gas are important parameters for spoilage microbiota and shelf-life of broiler meat, while the individual broiler flocks display no significant difference in microbiota during shelf-life of the retail packaged broilers if slaughter and packaged under the same conditions. Highlighting 
the important role of the production environment, as a route of contamination, for spoilage microorganisms, such as Brochothrix and Janthinobacterium.

Furthermore, our results indicate that the relative abundance of a potentially pathogenic Serratia species increase during shelf-life in high oxygen MAP, even though in a low relative abundance, and it is apparently able to multiply in retail packaged broiler meat kept at refrigeration temperature, which could potentially be a food safety issue. However, we were not able to identify Serratia in the abattoir production environment.

Using $16 \mathrm{~S}$ rRNA amplicon sequencing allowed us easily to identify the microbiota on retail packaged broiler meat during shelf-life, without being reliant on traditional cultivation steps. The 16S rRNA amplicon sequencing method is not absolutely quantitative, making it impossible to translate our relative abundance into actual abundance of the individual genera. However, we can still compare the relative abundance of different OTUs and genera in different samples and how it changes between storage time and different broiler flocks. For interpretation of actual abundance levels we will be reliant on using a supporting quantitative method since an of increase of around 6 $\log _{10}$ CFUon retail broilers from day zero to sixteen was observed which resulted in sensory rejection at around 8-12 days after slaughter that was combined with CFUs higher than $10^{7}$ $\mathrm{CFU} / \mathrm{cm}^{2}$. The high colony counts of Brochothrix, lactic acid bacteria, and Gram negative selective agars fits the findings of very high relative abundance of both Brochothrix, Gram negative Janthinobacterium, and lactic acid bacteria, such as Carnobacterium and Vagococcus, identified on spoiled broilers by $16 \mathrm{~S}$ rRNA amplicon sequencing. Our results show that using $16 \mathrm{~S}$ rRNA amplicon sequencing can help us identify bacterial genera not previously associated as putative spoilage bacteria of meat which in the future can expand our horizon on the microbial composition of food products of animal origin. 


\section{Conclusion}

We confirmed the hypothesis that there is no significant difference in the microbiota between retail broiler meat, when flocks are slaughtered and MAP packaged under the same conditions. The $16 \mathrm{~S}$ rRNA amplicon sequencing allowed us easily to identify the broiler microbiota during shelf-life, including well known spoilers Brochothrix, Carnobacterium, and Janthinobacterium species, and for the first time identify Vagococcus species as a dominating part of the late shelf-life microbiota on retail whole broiler meat in $80 \% \mathrm{O}_{2} / 20 \% \mathrm{CO}_{2} \mathrm{MAP}$. Dominating initial whole broiler meat microbiota, including Lactobacillus, Bacillus, Chryseobacterium and Flavobacterium species, is rapidly outgrown by Brochothrix, Carnobacterium, Janthinobacterium and Vagococcus species during storage in $80 \% \mathrm{O}_{2} / 20 \% \mathrm{CO}_{2} \mathrm{MAP}$ at $6^{\circ} \mathrm{C}$. The microbiota encompassing putative spoilage bacteria was dominant already four to eight days after slaughter, and acceptable shelf-life of whole broiler meat in $80 \% \mathrm{O}_{2} / 20 \% \mathrm{CO}_{2} \mathrm{MAP}$ was around 8-12 days, where total viable count was above $10^{7} \mathrm{CFU} / \mathrm{cm}^{2}$ and sensory rejection was mainly associated with sour smell formation. A potential major route of contamination for J. lividum is the cooling condenser in the broiler abattoir production line.

\section{Funding information}

This work was supported financially by Fjerkræafgiftsfonden (www.fa-fonden.dk). The funders had no role in the experimental design of this study, the collection and interpretation of data, or the decision to submit this work for publication. The authors declare no interest. 


\section{Acknowledgements}

We are expressing our gratitude to laboratory technicians Gitte Petersen, Katrine Aagaard, and trainee Mille Sofie Lund-Rasmussen who assisted collecting and processing samples and to the staff at the slaughter houses who made the material available for the study and assisted us the sampling.

\section{References}

Albertsen, M., Karst, S. M., Ziegler, A. S., Kirkegaard, R. H., Nielsen, P. H., 2015. Back to basics the influence of DNA extraction and primer choice on phylogenetic analysis of activated sludge communities. PLoS One 10, e0132783.

Barakat, R. K., Griffiths, M. W., Harris, L.J., 2000. Isolation and characterization of Carnobacterium, Lactococcus, and Enterococcus spp. from cooked, modified atmosphere packaged, refrigerated, poultry meat. Int. J. Food Microbiol. 62, 83-94.

Caporaso, J. G., Lauber, C. L., Walters, W. A., Berg-Lyons, D., Huntley, J., Fierer, N., Owens, S. M., Betley, J., Fraser, L., Bauer, M., Gormley, N., Gilbert, J. A., Smith, G., Knight, R., 2012. Ultrahigh-throughput microbial community analysis on the Illumina HiSeq and MiSeq platforms. ISME J. 6, 1621-1624.

Chaillou, S., Chaulot-Talmon, A., Caekebeke, H., Cardinal, M., Christieans, S., Denis, C., Desmonts, M. H., Dousset, X., Feurer, C., Hamon, E., Joffraud, J.J., La Carbona, S., Leroi, F., Leroy, S., Lorre, S., Mace, S., Pilet, M. F., Prevost, H., Rivollier, M., Roux, D., Talon, R., Zagorec, M., Champomier-Verges, M.C., 2015. Origin and ecological selection of core and food-specific bacterial communities associated with meat and seafood spoilage. ISME J. 9, 1105-1118. 
Daud, H. B., McMeekin, T. A., Thomas, C. J., 1979. Spoilage association of chicken skin. Appl. Environ. Microbiol. 37, 399-401.

Doulgeraki, A. I., Ercolini, D., Villani, F., Nychas, G. J. E., 2012. Spoilage microbiota associated to the storage of raw meat in different conditions. Int. J. Food Microbiol. 157, 130-141.

Edgar, R.C., 2013. UPARSE: highly accurate OTU sequences from microbial amplicon reads. Nat. Methods 10, 996-998.

Eneroth, A., Ahrne, S., Molin, G., 2000. Contamination routes of Gram-negative spoilage bacteria in the production of pasteurised milk, evaluated by randomly amplified polymorphic DNA (RAPD). Int. Dairy J. 10, 325-331.

Jaffres, E., Prevost, H., Rossero, A., Joffraud, J. J., Dousset, X., 2010. Vagococcus penaei sp. nov., isolated from spoilage microbiota of cooked shrimp (Penaeus vannamei). Int. J. Syst. Evol. Microbiol. 60, 2159-2164.

Jimenez, S. M., Salsi, M. S., Tiburzi, M. C., Rafaghelli, R. C., Tessi, M. A., Coutaz, V. R., 1997. Spoilage microflora in fresh chicken breast stored at 4 degrees $C$ : influence of packaging methods. J. Appl. Microbiol. 83, 613-618.

Kim, O. S., Cho, Y. J., Lee, K., Yoon, S. H., Kim, M., Na, H., Park, S. C., Jeon, Y. S., Lee, J. H., Yi, H., Won, S., Chun, J., 2012. Introducing EzTaxon-e: a prokaryotic 16S rRNA gene sequence database with phylotypes that represent uncultured species. Int. J. Syst. Evol. Microbiol. 62, 716721. 
Koort, J., Murros, A., Coenye, T., Eerola, S., Vandamme, P., Sukura, A., Bjorkroth, J., 2005. Lactobacillus oligofermentans sp. nov., associated with spoilage of modified-atmosphere-packaged poultry products. Appl. Environ. Microbiol. 71, 4400-4406.

Leisner, J. J., Laursen, B. G., Prevost, H., Drider, D., Dalgaard, P., 2007. Carnobacterium: positive and negative effects in the environment and in foods. FEMS Microbiol. Rev. 31, 592-613.

Liang, R. R., Yu, X. Q., Wang, R. H., Luo, X., Mao, Y. W., Zhu, L. X., Zhang, Y. M., 2012. Bacterial diversity and spoilage-related microbiota associated with freshly prepared chicken products under aerobic conditions at $4{ }^{\circ} \mathrm{C}$. J. Food Prot. 75, 1057-1062.

McIlroy, S. J., Saunders, A. M., Albertsen, M., Nierychlo, M., McIlroy, B., Hansen, A.A., Karst, S. M., Nielsen, J. L., Nielsen, P. H., 2015. MiDAS: the field guide to the microbes of activated sludge. Database 2015, 1-8.

Mossad, S.B., 2000. The world's first case of Serratia liquefaciens intravascular catheter-related suppurative thrombophlebitis and native valve endeocarditis. Clin. Microbiol. Infect. 6, 559-560

Nieminen, T. T., Koskinen, K., Laine, P., Hultman, J., Sade, E., Paulin, L., Paloranta, A., Johansson, P., Bjorkroth, J., Auvinen, P., 2012. Comparison of microbial communities in marinated and unmarinated broiler meat by metagenomics. Int. J. Food Microbiol. 157, 142-149.

Nieminen, T. T., Nummela, M., Bjorkroth, J., 2015. Packaging gas selects lactic acid bacterial communities on raw pork. J. Appl. Microbiol. 119, 1310-1316. 
Penney, N., Hagyard, C. J., Bell, R. G., 1993. Extension of shelf-life of chilled sliced roast beef by carbon-dioxide packaging. Int. J. Food Sci. Technol. 28, 181-191.

Powell, S. M., Tamplin, M. L., 2012. Microbial communities on Australian modified atmosphere packaged Atlantic salmon. Food Microbiol. 30, 226-232.

Rahkila, R., Nieminen, T., Johansson, P., Sade, E., Bjorkroth, J., 2012. Characterization and evaluation of the spoilage potential of Lactococcus piscium isolates from modified atmosphere packaged meat. Int. J. Food Microbiol. 156, 50-59.

Rouger, A., Moriceau, N., Prévost, H., Remenant, B., Zagorec, M., 2018. Diversity of bacterial communities in French chicken cuts stored under modified atmosphere packaging. Food Microbiol. 70, 7-16.

RStudioTeam, 2015. RStudio: Integrated Development for R. http://www.rstudio.com/ (accessed 29 November 2018).

Sade, E., Murros, A., Bjorkroth, J., 2013. Predominant enterobacteria on modified-atmosphere packaged meat and poultry. Food Microbiol. 34, 252-258.

Thomas, N. L., 1978. Observations of the relationship between the surface area and weight of eviscerated carcases of chickens, ducks and turkeys. Int. J. Food Sci. Technol. 13, 81-86.

Vihavainen, E., Lundstrom, H. S., Susiluoto, T., Koort, J., Paulin, L., Auvinen, P., Bjorkroth, K. J., 2007. Role of broiler carcasses and processing plant air in contamination of modified-atmosphere- 
packaged broiler products with psychrotrophic lactic acid bacteria. Appl. Environ. Microbiol. 73, 1136-1145.

Ward, D. V., Gevers, D., Giannoukos, G., Earl, A. M., Methe, B. A., Sodergren, E., Feldgarden, M., Ciulla, D. M., Tabbaa, D., Arze, C., Appelbaum, E., Aird, L., Anderson, S., Ayvaz, T., Belter, E., Bihan, M., Bloom, T., Crabtree, J., Courtney, L., Carmichael, L., Dooling, D., Erlich, R. L., Farmer, C., Fulton, L., Fulton, R., Gao, H. Y., Gill, J.A., Haas, B. J., Hemphill, L., Hall, O., Hamilton, S. G., Hepburn, T. A., Lennon, N. J., Joshi, V., Kells, C., Kovar, C. L., Kalra, D., Li, K., Lewis, L., Leonard, S., Muzny, D. M., Mardis, E., Mihindukulasuriya, K., Magrini, V., O'Laughlin, M., Pohl, C., Qin, X., Ross, K., Ross, M.C., Rogers, Y. H. A., Singh, N., Shang, Y., Wilczek-Boney, K., Wortman, J. R., Worley, K. C., Youmans, B. P., Yooseph, S., Zhou, Y., Schloss, P. D., Wilson, R., Gibbs, R. A., Nelson, K. E., Weinstock, G., DeSantis, T. Z., Petrosino, J. F., Highlander, S. K., Birren, B. W., Jumpstart Consortium Human, M., 2012. Evaluation of 16S rDNA-based community profiling for human microbiome research. PLoS One 7, e39315. 


\section{Legend to figures}

Fig. 1. Overall acceptability (organoleptic shelf life) of retail broiler meat samples. Score $1=$ Acceptable, score 2 = not acceptable. Danish broiler flocks were not sampled on day 1 , while the Norwegian broiler flock was not sampled on day 0 .

Fig. 2. Total psychrotrophic viable count $\left(\log _{10} \mathrm{CFU} / \mathrm{cm}^{2}\right)$ on retail broiler meat 0-16 days after slaughter. The sample from flock 1 day 4 was not collected. Samples on PCA from flock 4 day 0 (40) and flock 6 day 8 (6-8), were contaminated and have been removed from the CFU data.

Fig. 3. Heatmap displaying the microbiota relative abundance of top 21 genera, isolated from Danish retail broiler meat and abattoir production line carcass and swab samples. Labelled by day after slaughter $(0=$ day $0,4=$ day $4,8=$ day $8,10=$ day $10,12=$ day $12,16=$ day 16$)$ (retail meat $)$ or sampling type and place (production line).

Fig. 4. Heatmap of the relative abundance of top 5 phyla identified in Danish whole broiler meat microbiota during and exceeding shelf-life (X-axis = days after slaughter).

Fig. 5. Boxplot of the relative abundance top 15 genera identified in Danish whole broiler meat microbiota during and exceeding shelf-life, flocks pooled and grouped by days after slaughter. The boxes include the inter-quartile range (25-75\% of data), with the median indicated and the whiskers 
being the lowest inter-quartile $-1.5 \times$ inter-quartile range and highest inter-quartile $+1.5 \times$ interquartile range, respectively. The outliers are shown as dots.

Fig. 6. PCoA of microbiota from abattoir production line, carcass and swab samples, principal component 1 and 2 (PC1 \& PC2). Data points with the same colour and connected by lines refer to the same day of sampling. Bacterial names refer to loadings of the top 25 OTUs. 
Fig. 1

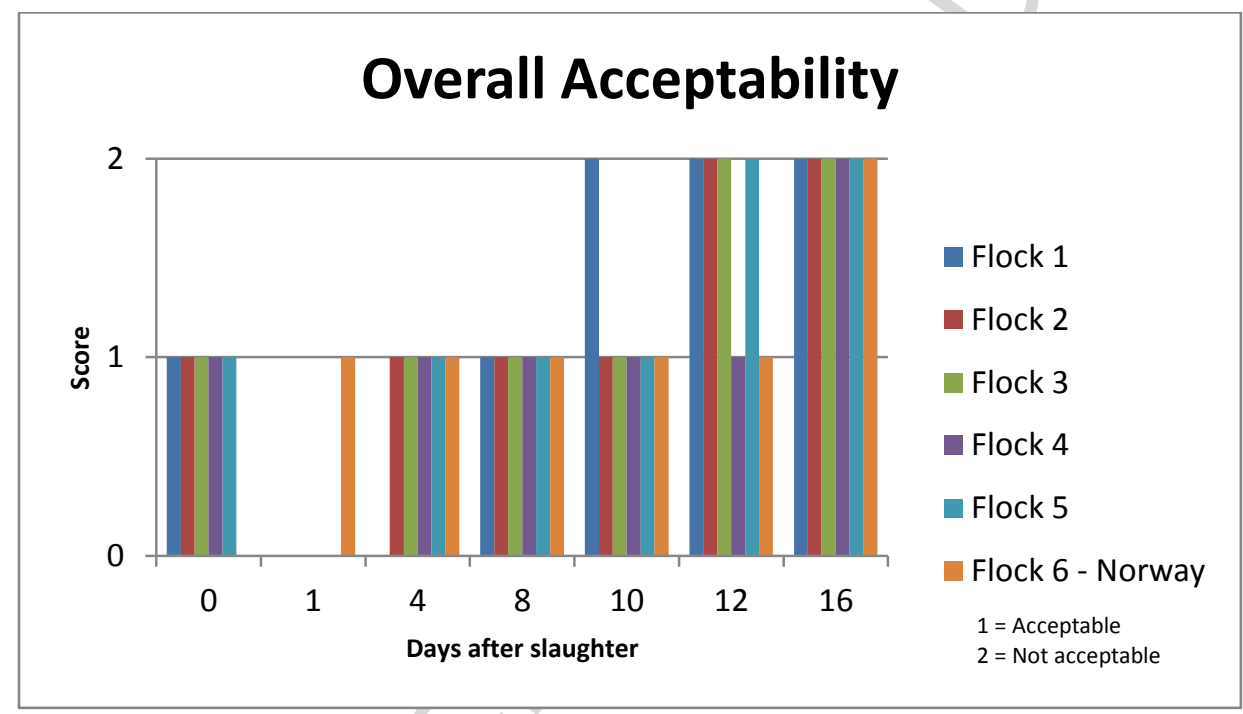


Fig. 2

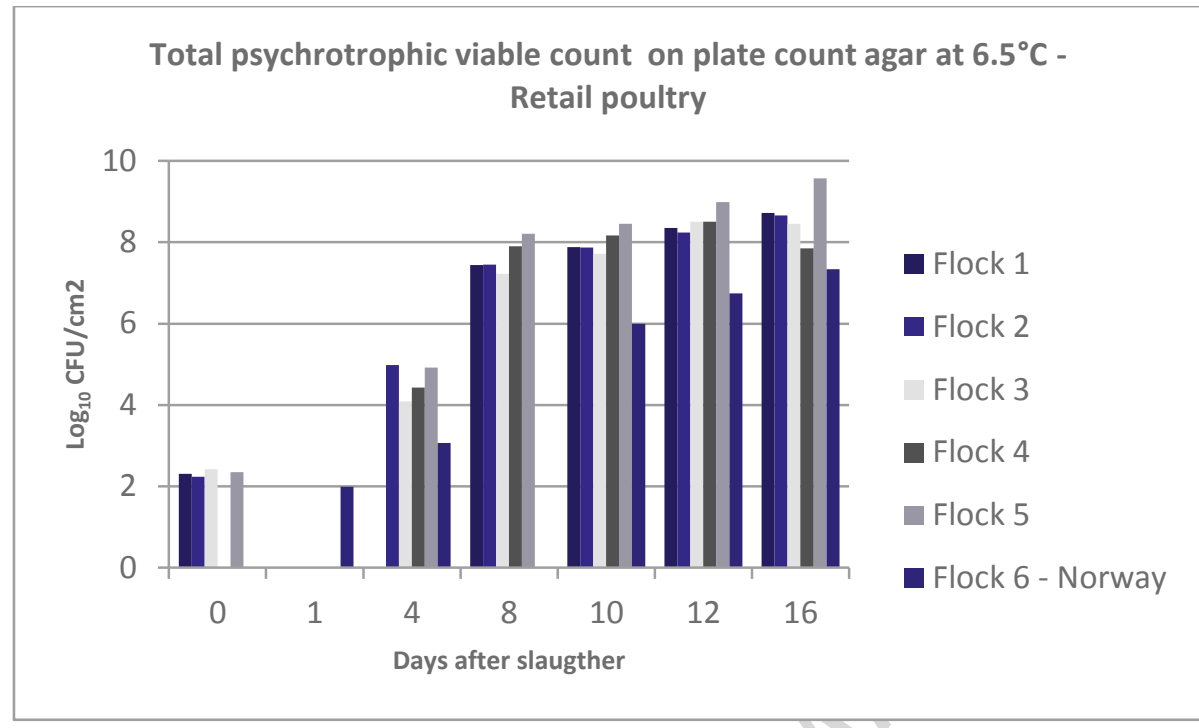


Fig. 3

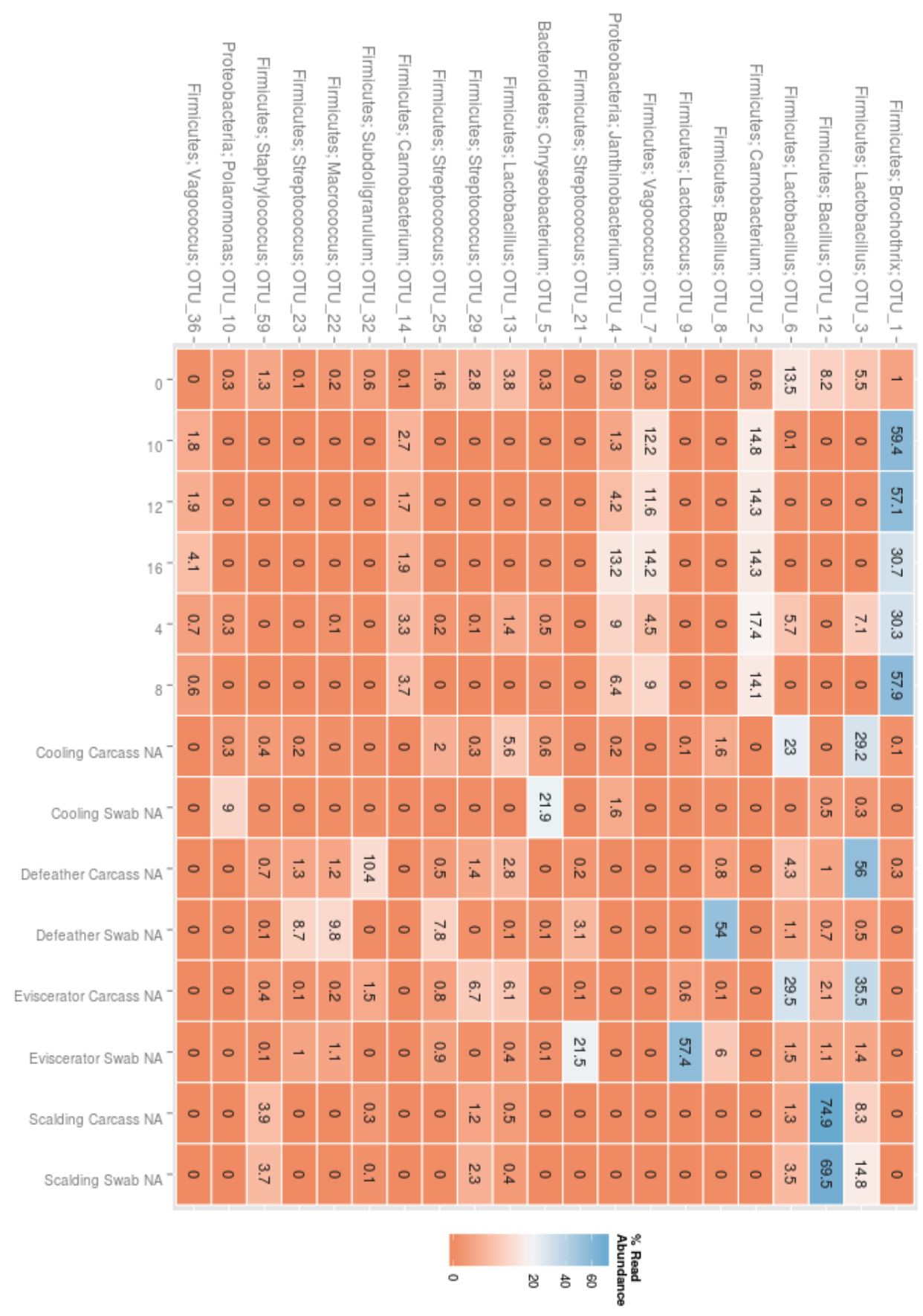


Fig. 4

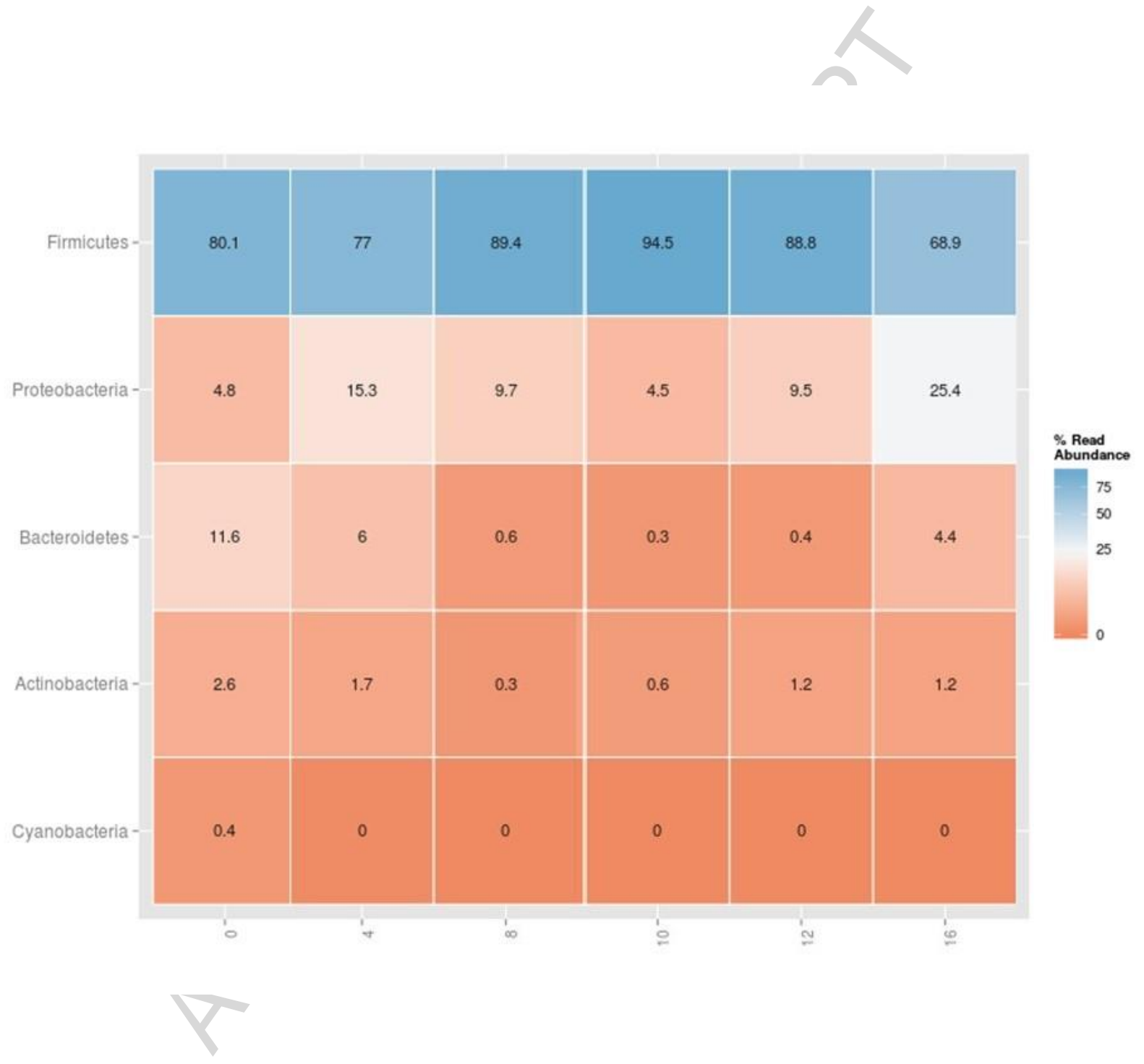


Fig. 5

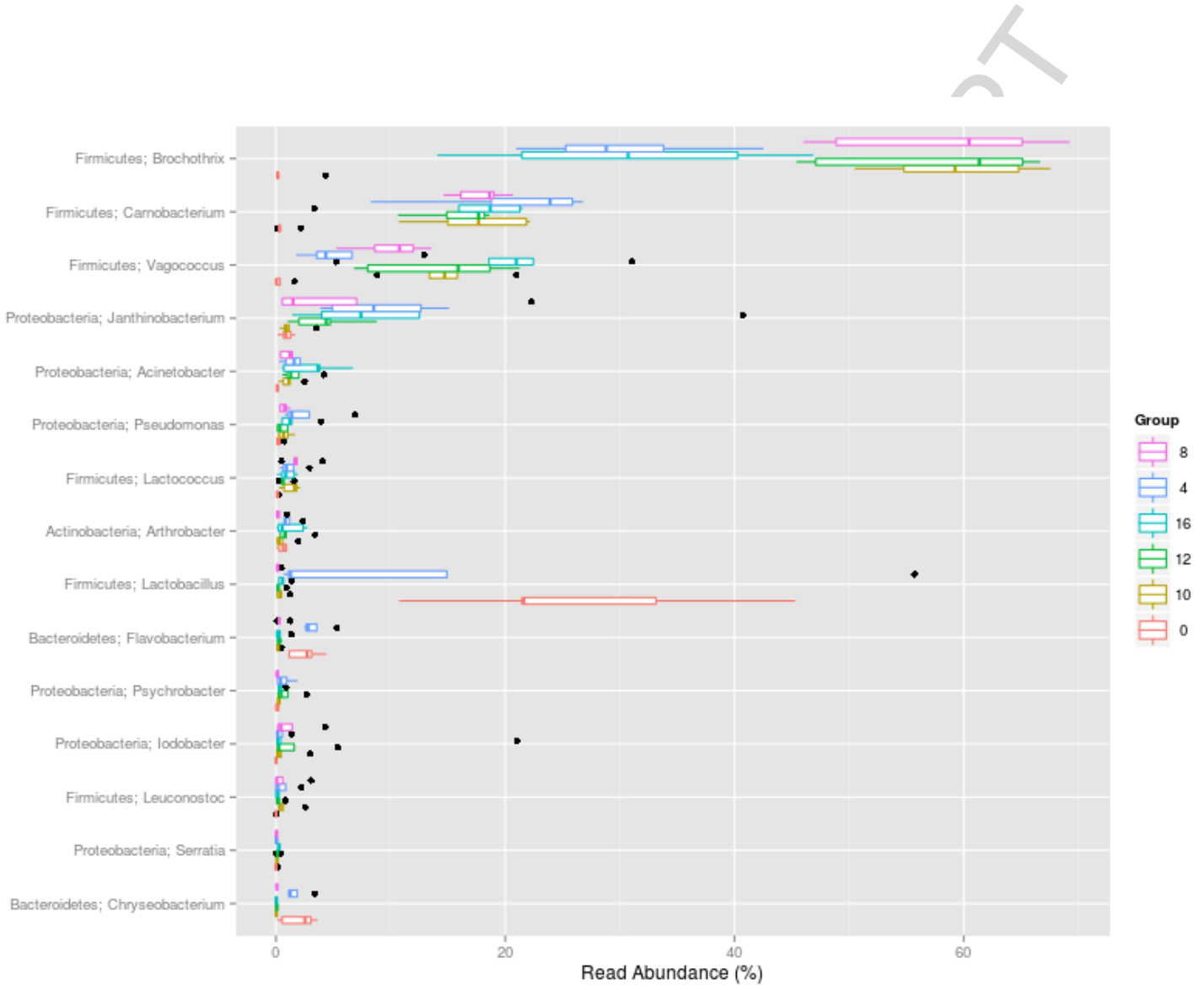


Fig. 6

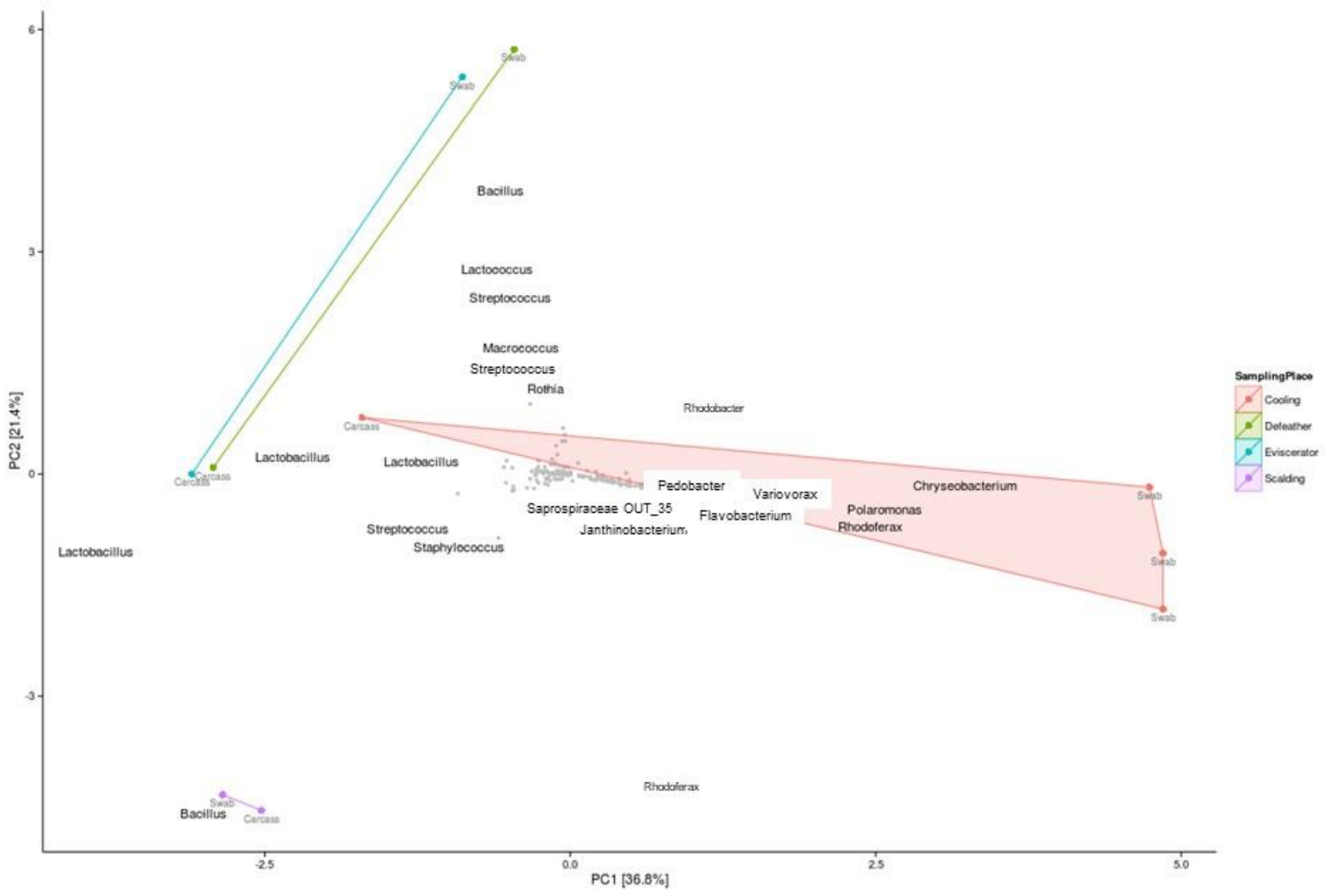




\section{Highlights}

- The microbiota of broiler carcasses encompassing putative spoilage bacteria was dominant already four to eight days after slaughter

- The acceptable shelf-life of whole broiler meat in $80 \% \mathrm{O}_{2} / 20 \% \mathrm{CO}_{2} \mathrm{MAP}$ was around 8-12 days

- The spoilage microbiota was quite similar between flocks

- The core microbiota encompassing putative spoilage bacteria consisted of Brochothrix, Carnobacterium and Vagococcus 